\section{Garden Chrysanthemums 'Peach Centerpiece' and 'Sesquicentennial Sun'}

\author{
Neil Anderson ${ }^{1}$, Peter Ascher ${ }^{2}$, and Esther Gesick ${ }^{3}$ \\ Department of Horticultural Science, University of Minnesota, St. Paul, \\ MN 55108
}

Brad Walvatne
Lake Country Gardens, Battle Lake, MN 56515

Neal Eash

Southwestern Research and Outreach Center, Lamberton, MN 56162

Vince Fritz and Jim Hebel

Southern Research and Outreach Center, Waseca, MN 56093

Steve Poppe

West Central Research and Outreach Center, Morris, MN 56267

\section{Roger Wagner \\ University of Minnesota-Crookston Campus, Crookston, MN 56717}

\section{Dave Wildung}

North Central Research and Outreach Center, Grand Rapids, MN 55744

Additional index words. Asteraceae, chrysanthemum breeding, Dendranthema, winter hardiness, herbaceous perennials

Chrysanthemums [Dendranthema $\times$ grandiflora Tzvelv. (syn. Chrysanthemum $\times$ morifolium Ramat.)], members of the Asteraceae Dumort., have been bred at the Univ. of Minnesota since 1924, with the initiation by C.E. Cary of greenhouse chrysanthemums (1924-29) and continued by L.E. Longley with garden chrysanthemums (192949), R.E. Widmer (1949-88), P.D. Ascher (1988-99), and currently N.O. Anderson (Widmer, 1997). The breeding program focused initially on greenhouse chrysanthemums (seven cultivars were subsequently released during 1935-40), and later on garden types (77 released since 1939). Early flowering and blooming prior to a killing frost or freeze were the first breeding objectives for garden chrysanthemums. Subsequently, plant habit and stem strength were improved, leading to the release of a popular cultivar-group of "cushion" habit garden chrysanthemums, the Minn Group. The most popular cultivar is 'Minngopher', which revolutionized the industry (Widmer, 1997). Private breeding companies followed this ideotype, releasing cultivars with the cushion habit, which now cap-

Received for publication 12 Dec. 2000. Accepted for publication 20 Mar 2001. Scientific Journal Series Paper No. 001210063 of the Dept. of Horticultural Science. This research has been supported in whole or in part by the Minnesota Agricultural Experiment Station.

${ }^{1}$ Assistant Professor; to whom reprint requests should be addressed.E-mail address: ander044@tc.umn.edu ${ }^{2}$ Professor Emeritus.

${ }^{3}$ Research Fellow. ture the majority of market share (van Zanten, North America, 1999; Yoder Brothers, 2000).

'Peach Centerpiece' and 'Sesquicentennial Sun' are garden chrysanthemums released in 2000 and 2001, respectively, by the Univ. of Minnesota herbaceous perennial breeding program. Breeding and selection for complete frost tolerance of petals, extended flowering

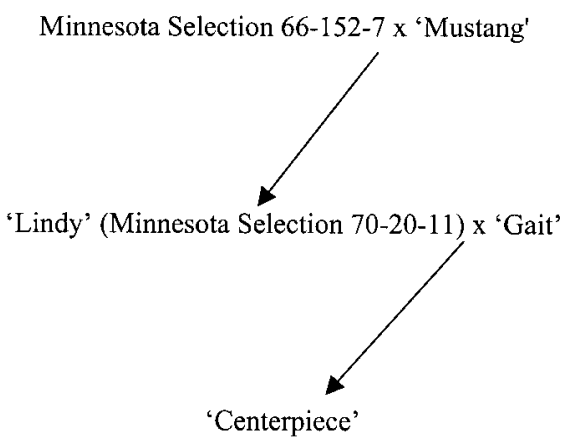

(Minnesota Selection 77-94-31)

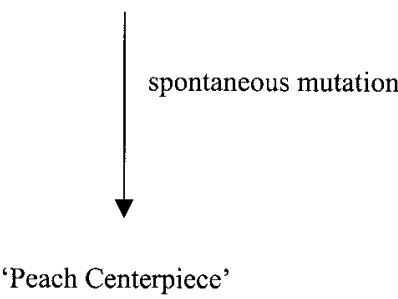

Fig. 1. Pedigree of Dendranthema $\times$ grandiflora 'Peach Centerpiece' and its parental source 'Centerpiece'. duration, moderate winter hardiness, improved stem strength, cushion plant habit, and gold flower color led to the selection of 'Sesquicentennial Sun'.

'Sesquicentennial Sun' is being offered as a new and improved replacement for 'Centennial Sun', a 1985 release that is not frost tolerant; 'Sesquicentennial Sun' is moderately frost tolerant. The two cultivars have similar flower color, flower form, and floral display. 'Sesquicentennial Sun' has a more compact flowering habit than 'Centennial Sun'. In sideby-side comparison trials, 'Sesquicentennial Sun' proved to be a season extender that outperformed 'Centennial Sun' later in the fall after a frost.

'Peach Centerpiece' is a spontaneous mutation of 'Centerpiece'. Its superior qualities include moderately high winter hardiness, early flowering, superior stem strength, upright plant habit, above-average frost tolerance of petals, and an attractive peach flower color. Stock plants of both cultivars have been distributed to commercial herbaceous perennial and nursery growers for propagation.

\section{Origin}

'Peach Centerpiece' is a sport of 'Centerpiece', found by Brad Walvatne, Lake Country Gardens, Battle Lake, Minn., and offered to the Univ. of Minnesota for release. It is the 76th chrysanthemum released by the Univ. of Minnesota breeding program. 'Centerpiece' was released in 1982, the result of crossing 'Lindy' x 'Gait' (Fig. 1) (Widmer et al., 1981). 'Peach Centerpiece' is a spontaneous mutation that arose under normal greenhouse growing conditions for chrysanthemums (Dole and Wilkins, 1999). The name 'Peach Centerpiece' was chosen based on the peach-colored flowers, sharing the same size and flower form of 'Centerpiece'.

'Sesquicentennial Sun', Minnesota selection 95-161-2, is an $\mathrm{F}_{1}$ hybrid from the cross 'Bandit' x 'Allure' made in 1994 (Fig. 2). The pedigrees for 'Bandit' and 'Allure' are proprietary and unavailable (Yoder Brothers, 2000). 'Sesquicentennial Sun' was the only selection from the cross progeny $(n=8)$ during field performance trials in 1995 , conducted on the St. Paul campus $\left(45^{\circ} \mathrm{N}\right.$ lat.). It is the 77 th cultivar released from the breeding program. 'Sesquicentennial Sun' was named in honor of

$$
\text { 'Bandit' x 'Allure' }
$$

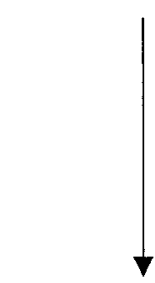

$$
\text { 'Sesquicentennial Sun' }
$$

(Minnesota Selection 95-161-2)

Fig. 2. Pedigree of Dendranthema $\times$ grandiflora 'Sesquicentennial Sun'. 


\section{Cultivar \& Germplasm Releases}

the Univ. of Minnesota sesquicentennial celebration and it resembles 'Centennial Sun' in flower color, form, and size.

\section{Description and performance}

'Peach Centerpiece' produces a thick canopy of 2.25-4 inch $(5.5-10 \mathrm{~cm})$ peachcolored flowers (Table 1) on an upright plant (Fig. 3). As with all members of the Asteraceae, each flower is a composite head or inflorescence clustered in corymbs with multiple ray (petaloid, gynoecious) and/or disc (apetalous, hermaphroditic) florets, each with a single ovule (Anderson et al., 1988). The ray florets of each inflorescence are quilled (rolled) petals that classify as RHS red group 36B (Royal Horticultural Society, 1995), frequently terminating with a flattened or spoon tip with the color RHS red group 37A. The quill and spoon sections of each ray petal fade to a color of RHS red group 36D. Each ray floret is $6 \pm 1 \mathrm{~cm}$ in length and $0.5 \pm 0.01 \mathrm{~cm}$ wide and rounded at the apex with an attenuate base; the margins are entire with a glabrous texture. Floral display is profuse at the peak flower period, with a full canopy of flowers covering the top of each plant.

First-year 'Peach Centerpiece' plants grow to $18-32$ inches $(45-75 \mathrm{~cm})$ wide and $14-31$ inches $(35-77.5 \mathrm{~cm})$ high (Table 1). The plant stem color is RHS red-purple group 60B. The long stems, adorned with dark green foliage, create an upright plant habit that makes 'Peach Centerpiece' a good cultivar for cut flowers. Leaf arrangement is alternate. Length of fully expanded leaves is $8 \pm 1 \mathrm{~cm}$ and widths are 4 $\pm 2 \mathrm{~cm}$. Leaf apices are rounded while the leaf bases are aequilateral. As with all garden chrysanthemums, the leaf margins are deeply incised, resembling a mulberry (Morus sp.) leaf, with a hirsute texture. Leaf petioles are $3 \pm 0.5$ $\mathrm{cm}$ long. Fully expanded leaves have a color of RHS green group 137B (adaxial surface) and RHS yellow-green group 147B (abaxial surface).

The vigorous, uniform plants usually begin blooming the first week of September (7week short-day response group, a midseason cultivar) and continue flowering until a killing frost (occurring between Oct. $15-31$ ) at $45^{\circ} \mathrm{N}$ lat. Flower petals possess intermediate frost resistance in Minnesota field trials at Waseca, St. Paul (USDA Zone 4), Morris (USDA Zone 3/4), and Grand Rapids, Crookston (USDA Zone 3). In replicated field trials conducted in 1999 without mulch or any winter protection, winter survival averaged $80 \%$ (normal growth with no damage evident) in USDA Zones 3-4 (Table 1 ). On average, only $1.2 \%$ were completely killed.

A bouquet of frost-tolerant golden flowers makes 'Sesquicentennial Sun' a fine introduction in honor of the Univ. of Minnesota's 150th anniversary year, the sesquicentennial (Fig. 4). This cultivar produces a profuse flower display of $1-2$ inches $(2.5-5 \mathrm{~cm})$, fully double pompon flowers (Table 1). Each inflorescence contains primarily ray florets (as flattened petals) that are golden yellow. The adaxial petal surface matches RHS yellow group 13A,
Table 1. Plant growth characteristics and winter hardiness of 'Peach Centerpiece' and 'Sesquicentennial Sun' garden chrysanthemums grown in replicated trials at four sites in Minnesota in 1999. All sites had 10 replications/cultivar except for St. Paul (24 replications).

\begin{tabular}{|c|c|c|c|c|c|c|c|c|c|c|}
\hline \multirow[b]{2}{*}{ Trait } & \multicolumn{5}{|c|}{ Peach Centerpiece } & \multicolumn{5}{|c|}{ Sesquicentennial Sun } \\
\hline & St. Paul & Waseca & Morris & $\begin{array}{l}\text { Grand } \\
\text { Rapids }\end{array}$ & Mean & St. Paul & Waseca & Morris & $\begin{array}{l}\text { Grand } \\
\text { Rapids }\end{array}$ & Mean \\
\hline \multicolumn{11}{|c|}{ Plant morphology (inches) } \\
\hline $\begin{array}{l}\text { Flower size } \\
\text { (inches) }\end{array}$ & 3.2 & 2.2 & 3.1 & 4.0 & 3.2 & 1.8 & 1.0 & 2.0 & 1.8 & 1.7 \\
\hline $\begin{array}{l}\text { Plant height } \\
\text { (inches) }\end{array}$ & 20.0 & 14.0 & 31.0 & 19.0 & 21.0 & 18.0 & 12.0 & 15.5 & 12.0 & 14.4 \\
\hline $\begin{array}{l}\text { Plant width } \\
\text { (inches) }\end{array}$ & 21.0 & 18.0 & 32.0 & 23.0 & 23.5 & 17.0 & 14.0 & 23.0 & 15.5 & 17.4 \\
\hline \multicolumn{11}{|c|}{ Winter survival $(\%)^{z}$} \\
\hline $\begin{array}{l}\text { Normal growth } \\
\text { (no damage) }\end{array}$ & 95.0 & 100.0 & 100.0 & 25.0 & 80.0 & 100.0 & 84.0 & 90.0 & 40.0 & 78.5 \\
\hline Some injury & 0.0 & 0.0 & 0.0 & 75.0 & 18.8 & 0.0 & 0.0 & 10.0 & 10.0 & 5.0 \\
\hline $\begin{array}{l}\text { Weak, few } \\
\text { growing points }\end{array}$ & 0.0 & 0.0 & 0.0 & 0.0 & 0.0 & 0.0 & 16.0 & 0.0 & 40.0 & 14.0 \\
\hline Dead & 5.0 & 0.0 & 0.0 & 0.0 & 1.2 & 0.0 & 0.0 & 0.0 & 10.0 & 2.5 \\
\hline
\end{tabular}

${ }^{\mathrm{z}}$ Observations recorded in Spring 2000.

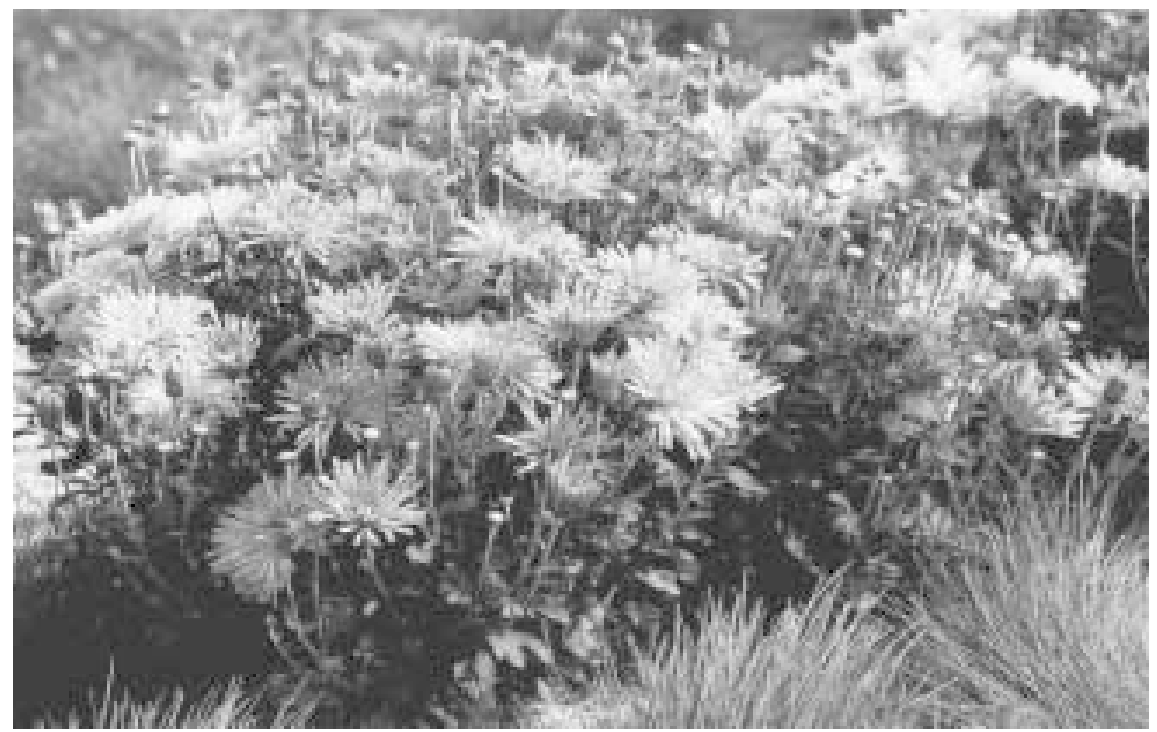

Fig. 3. 'Peach Centerpiece', with an upright growth habit, has long stems of peach-colored flowers suitable for use in floral arrangements.

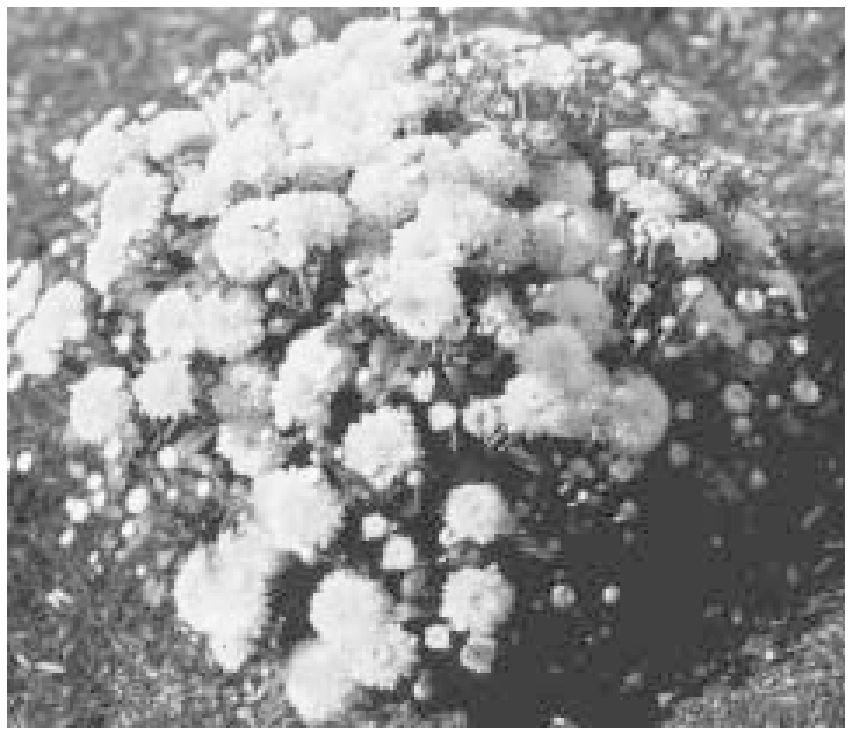

Fig. 4. 'Sesquicentennial Sun' at early flowering stage, displaying the cushion habit and pompon flowers on a first-year plant. 
while the abaxial surface is RHS yellow group 13B (Royal Horticultural Society, 1995). The ray petal coloration does not fade as the flowers age. Each ray floret is oblanceolate, is 2.5 $\pm 1 \mathrm{~cm}$ long $\times 0.5 \pm 0.01 \mathrm{~cm}$ wide, and is rounded at the apex with an attenuate base. The petal margins are entire with a glabrous texture. The floral display completely covers the cushion habit of each plant.

At the peak of flowering, first-year 'Sesquicentennial Sun' plants (raised from unpinched terminal cuttings) grow to $12-18$ inches (30-45 cm) high and 14-23 inches (35$62.5 \mathrm{~cm}$ ) wide (Table 1). Plant stem color is RHS red-purple group 60A; leaf arrangement is alternate. Fully expanded leaf dimensions are $7 \pm 2 \mathrm{~cm}$ in length and $5 \pm 1 \mathrm{~cm}$ in width. Leaf apices are cuspidate while the leaf bases are aequilateral. The deeply incised leaves are slightly hirsute in texture with $2 \pm 0.5 \mathrm{~cm}$ long petioles. Fully expanded leaves have a color of RHS green group 137C (adaxial surface) and RHS green group 138C (abaxial surface).

'Sesquicentennial Sun' is a short-season cultivar (6-week short-day response group). In southern Minnesota, flowering begins in early August, while in the St. Paul area and further north, it commences in late August to early September. Flowering continues until a killing freeze in mid- to late October. Flower petals possess intermediate to excellent frost resistance. 'Sesquicentennial Sun' has moderate to high winter hardiness; average survival (normal growth with no visual damage) in USDA Zones 4 and 3 was $92 \%$ and $40 \%$, respectively
(Table 1). Crowns of 'Sesquicentennial Sun' should be mulched in northern growing regions to maximize winter survival. Planting young, nonflowering specimens in flower borders in late spring or early summer is recommended.

\section{Culture}

'Peach Centerpiece' is suitable for pot plant culture and can be programmed to flower for spring and fall sales. 'Peach Centerpiece' may be grown as an herbaceous perennial, with moderately high winter hardiness. A profuse floral display, dark green foliage, and intermediate stem strength characterize 'Sesquicentennial Sun'. This cultivar adapts well to spring flowering in pots with either short or natural photoperiods to induce flowering. This cultivar is equally satisfactory for use as a cut flower and in flower borders.

Spring-flowering potted specimens of both cultivars purchased for Mother's Day or other spring holidays may be planted in gardens for fall flowering. Blooming plants purchased in pots late in the summer or early fall may be used to decorate patios, window boxes, etc., and may then be plunged into the ground in pots or planted in flower beds (pots removed) when summer blooming plants are no longer decorative. To ensure maximal winter survival as an herbaceous perennial, mulch the crowns of 'Peach Centerpiece' and 'Sesquicentennial Sun' in northern growing regions (USDA Zone 3). Planting young, nonflower- ing specimens in flower borders in late spring or early summer is recommended.

\section{Availability}

Stock plants were distributed for propagation by members of the Minnesota Nursery and Landscape Association in 2000. Information on sources of propagules may be obtained from Jim Stolzenburg, Secretary-Treasurer, Minnesota Nurserymen's Research Corporation, 1325 Bailey Road, St. Paul, MN 55119.

\section{Literature Cited.}

Anderson, N.O., B.E. Liedl, P.D. Ascher, R.E. Widmer, and S.L. Desborough. 1988. Evaluating self-incompatibility in Chrysanthemum. The influence of ovule number. Sexual Plant Reprod. $1: 173-181$.

Dole, J. and H.F. Wilkins. 1999. Floriculture: Principles and species. Prentice Hall, Upper Saddle River, N.J.

Royal Horticultural Society, The. 1995. RHS colour chart. Royal Hort. Soc., London.

van Zanten, North America. 1999. Garden mum catalog. van Zanten, N.A., Oxnard, Calif.

Widmer, R.E. 1997. A history of Minnesota floriculture. Minnesota Rpt. No. 238-1997, Minnesota Agr. Expt. Sta., St. Paul.

Widmer, R.E., P.D. Ascher, and M.C. Stuart. 1981. Centerpiece: New Minnesota mum for 1982. Univ. of Minnesota, Agr. Expt. Sta., Misc. Rpt. No. $172-81$.

Yoder Brothers, Inc. 2000. Pot mums, cut mums, and garden mum catalogs. Yoder Brothers, Barberton, Ohio. 